\title{
KOCKS ROTATION MILL [KRM] - AN INNOVATIVE ELONGATION METHOD FOR SEAMLESS TUBE*
}

\begin{abstract}
Erich Bartel ${ }^{1}$ Jörg Surmund ${ }^{2}$ Patrick Connel/ ${ }^{3}$

\section{Abstract}

The Kocks Rotation Mill - KRM- is an innovative elongation method for seamless tube production up to 4.5" diameter at production levels up to150,000 TPY. Using the principle of cross roll elongation, the machine rotates four rolls around the workpiece. A retained mandrel sets the wall thickness to a precision that exceeds existing industry norms. The KRM process performance has been truly excellent. Attributes include high billet weights, elongation of up to 9.5 in one pass, and eccentricity at or below $+/-$ $5.0 \%$. The flexibility of the process allows a wide range of steel grades to be produced at any wall thickness with little or no mill down time. Surface quality and yield are also greatly improved. Based upon the small foot print of the KRM rotor as well as the simple mandrel manipulation system, the installation cost of the KRM is significantly lower compared to other elongation methods. The reasonable cost of the machine, combined with greatly reduced foundation requirements, reduced ceiling height as well as simple utility connections reduce the initial investment for a new or upgraded mill. Finally, lower roll and mandrel costs allow high quality production at greatly reduces cost/ton. Keywords: Elongation; Seamless tube; Kocks; KRM.
\end{abstract}




\section{INTRODUCTION}

The Kocks Rotation Mill - KRM - is an innovative elongation method for seamless tube production in diameters up to 4.5 " $(114.3 \mathrm{~mm})$ at production levels up to 150,000 tpy. Using the principle of planetary cross roll elongation, the machine rotates four rolls around the work piece. A retained mandrel is used to set the wall thickness to a precision that greatly exceeds existing industry norms.

The KRM process performance has been truly excellent. Attributes include high billet weights, elongation of up to 9.5 in one pass, and eccentricity below $+/-5.0 \%$. The flexibility of the process allows a wide range of steel grades to be produced at any wall thickness with little or no mill down time. Surface quality and yield are also greatly improved.

Based upon the small foot print of the KRM as well as the simple mandrel manipulation system, the installation cost of the KRM is significantly lower compared to other elongation methods. The reasonable cost of the machine, combined with greatly reduced foundation requirements, reduced ceiling height as well as simple utility connections reduce the initial investment for a new or upgraded mill.

\subsection{Product History}

Seamless steel tube making processes can be grouped into three basic steps, piercing, elongation, and finally OD sizing. Further we can group these processes in to two basic categories as defined by the type of elongation process; longitudinal elongation and cross roll elongation.

Typical cross roll elongation, such as the Assel and Diescher process utilize either two or three rolls to elongate a pierced hollow. The freshly pierced hollow is rolled over an inserted mandrel, spinning and elongating under the effect of the deformation process. The "spinning" of the rolled stock creates stresses in the material, which can limit wall thickness possibilities and surface quality. These two cross roll processes are also limited to smaller average billet weights, with the resulting loss in yield due to a greater percentage of heavy ends. The advantage of the Assel and Diescher processes is that they can produce small volumes of reasonably good quality tube, with relatively low capital and tooling costs.

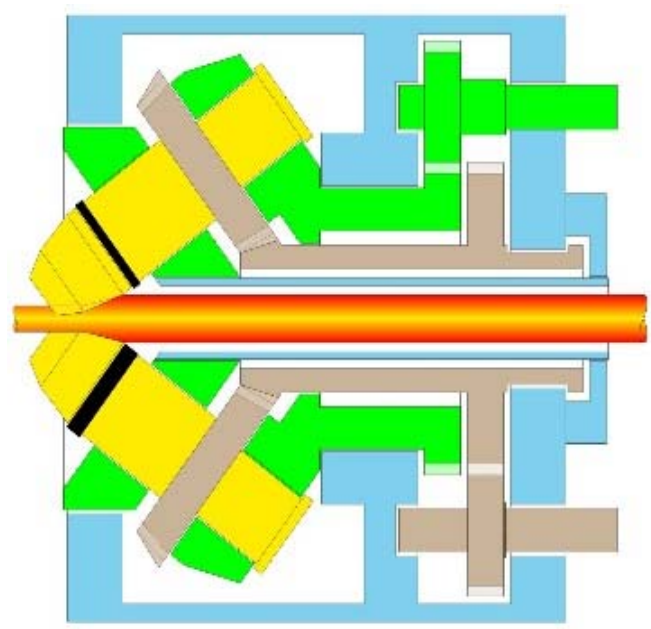

Figure1: KRM cross section. 
Longitudinal elongation methods like the modern continuous mandrel mills operate on the other end of the spectrum from traditional cross roll elongation methods. These processes use multiple stands of 2-roll or 3-roll design to roll a pierced hollow with an inserted mandrel to a desired OD and wall thickness.

They typically have very large footprints, tooling requirements and capital costs. The advantage of longitudinal elongation is that these processes can produce very large quantities of so-called mother tubes at high piece rates. However, this is also a disadvantage since this approach requires large quantities in order to be economically justified.

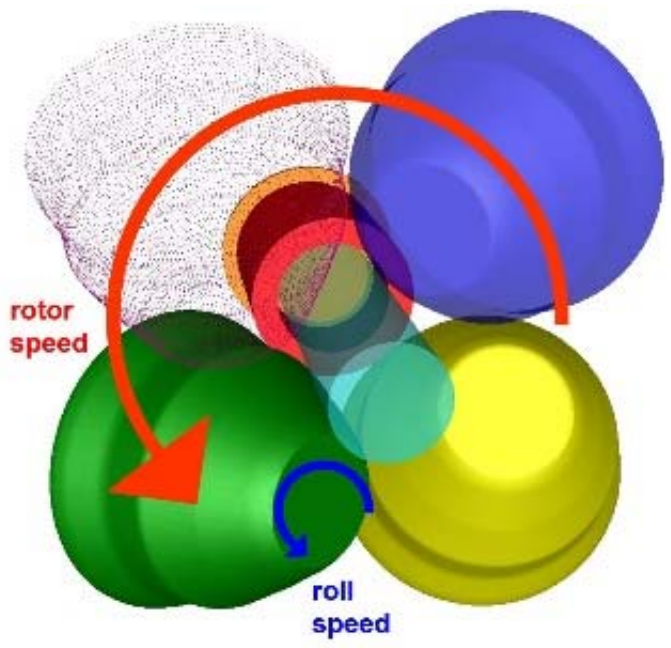

Figure 2: KRM rotor and roll

Historically, the debate has been longitudinal elongation (high volume, high capital cost) or cross roll elongation (low volume, low capital cost). The KRM was designed to fill the vast middle ground between these two solutions. Engineered, designed and built using long-utilized principles of mill-duty construction combined with efficient, high quality production, the KRM was born to revolutionize the elongation market. However, this revolution required testing and development.

\section{MATERIAL AND METHODS}

\subsection{Test Plant and Results}

The idea for a complete trial plant was hatched after trials at local production facilities became time prohibitive. The effort to develop this technology required a concentration of effort that was not possible at a location focused on production with an existing process line. These trials required a dedicated facility.

The Kocks Manufacturing facility in the northern German city of Bremen was chosen as the site location for the KRM trial plant. A warehouse, under construction at the time, was quickly converted to house this industrial grade trial plant. The main thrust of this effort was to install a facility that was as close to a true production facility as possible.

By starting with pre-pierced billets, the trial facility was able to begin production within 90 days of the start of the project. Over the 24 months that the plant was operated, over 1000 billets were rolled with wall thicknesses that ranged from $3 \mathrm{~mm}$ minimum to $16 \mathrm{~mm}$ maximum. Grades of material included basic steel like St52-3 to higher grades like X2CrNi19-11 and T-92. Despite a reheating furnace that imparted unusual amounts of scale on the pre-pierced billets, all of these grades and wall thickness were rolled successfully in the KRM plant with quality results that were truly impressive. 


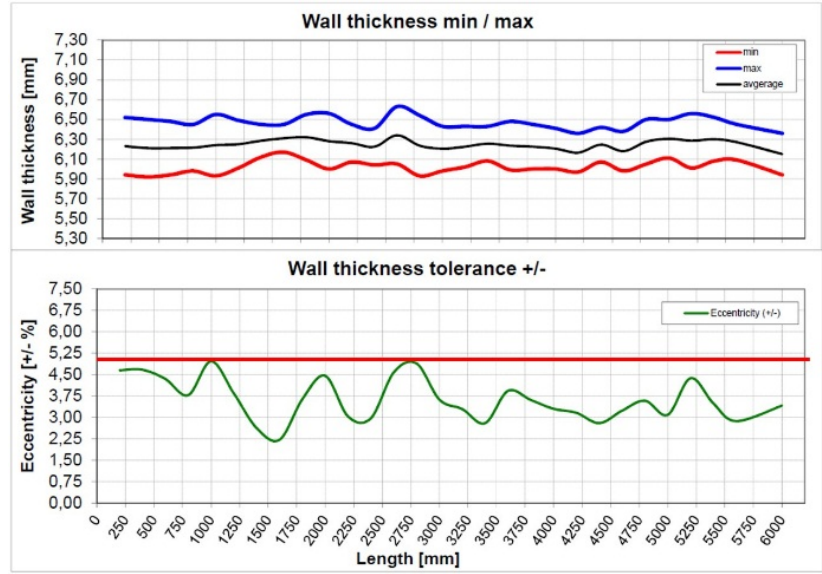

Figure 3: $6 \mathrm{~mm}$ wall thickness results

\subsection{KRM Operation Principle}

As stated above, the KRM operates using the basic principles of cross-rolling, with the exception that the four work rolls travel in a planetary movement around the workpiece. This allows a smooth deformation across the entire length of the hollow. The stresses imparted in more typical cross-rolling processes are not created with the KRM, allowing the production of long, thin-walled tubes with excellent.

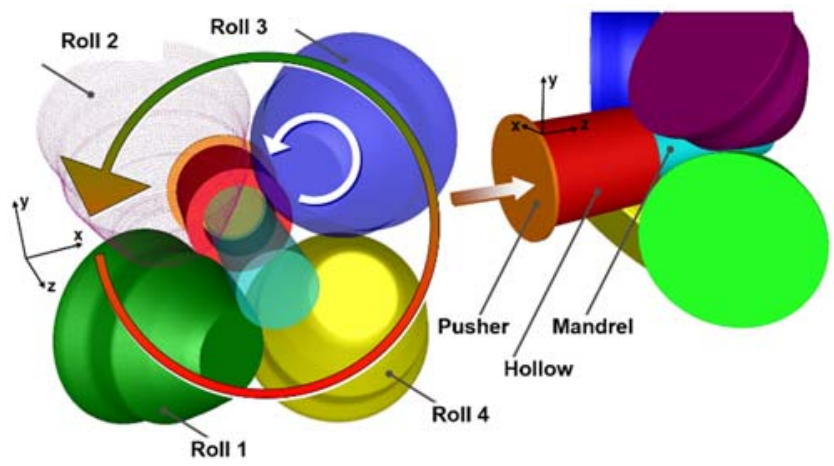

Figure 4: Operation principle

The working portion of the mandrel used in the KRM process is about equal in length to the actual pierced hollow. The mandrel moves with a controlled speed and the hollow is pushed wih a constant force while the work piece is in the elongator. As the mother tube leaves the $\mathrm{KRM}$, the mandrel is retracted and is then cooled and lubricated using a graphite coating.

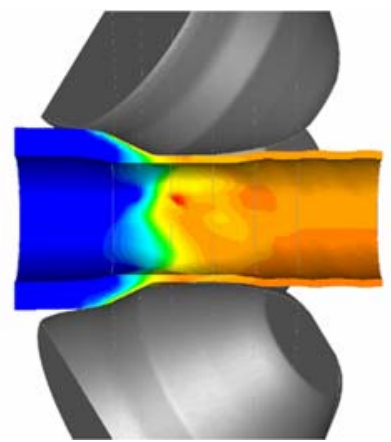

Figure 5: Deformation process 
The tube is stripped from the mandrel using the Kocks 3-roll extracting block (EXB). This 3-5 stand extractor performs two functions. The first is to help the mandrel to retract smoothly from the rolled tube. The second, equally important function is to size the mother tube OD to allow for finish processing. After the EXB, the product could easily be sold in a hot finished condition. However, more typically, it will be further processed in the 3-roll Stretch Reducing Block SRB ${ }^{\circledR}$ or cold drawing facility.

\subsection{Operating Performance}

The ability of the KRM to take up to 9.5 elongations in one pass, allows significant operational improvements. Only one billet diameter is used in the piercing area of the mill. The elimination of multiple sized billets allows the operation of the piercer to be greatly simplified. Now, every size tube starts with one billet size, resulting in a dramatic reduction in inventory.

The high deformation efficiency also has the benefit of allowing the piercing process to produce heavy wall hollows. Because heavy walls in the piercing process are easier to produce, less eccentricity is created. Less eccentricity in the piercing process translates into better tube quality in each subsequent production step. In total, three wall thicknesses can produce an entire range of finished tubes. Set-up time is reduced and production shows a corresponding increase.

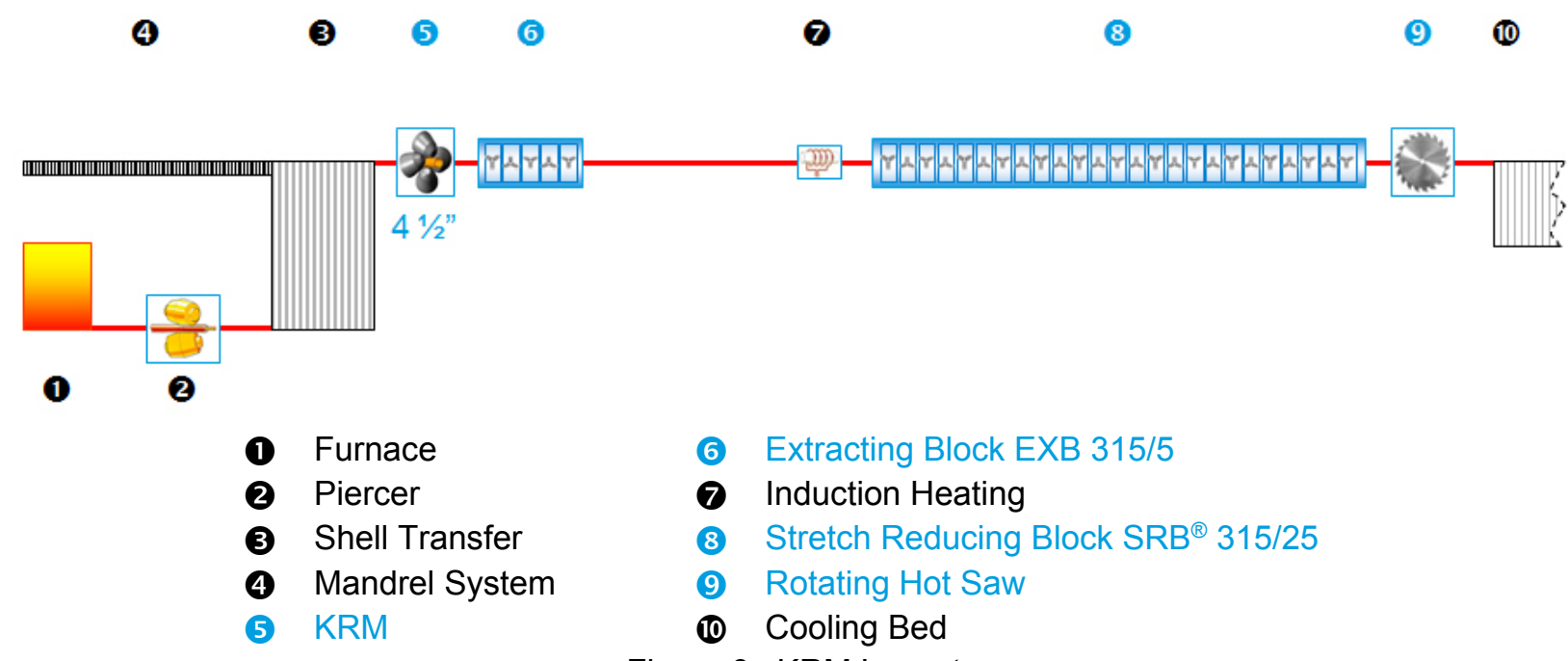

Figure 6: KRM Layout

The rolls on the KRM rotor are non-adjustable. This design principle has allowed for a very sturdy construction of the KRM that grants the possibility of producing tight tolerances in a very reliable process.

The productivity of this process is driven by quick rotor change and quick mandrel change. The KRM can be changed in less than 10 minutes. All required maintenance or roll change is done off-line. The total weight of the unit allows a relatively light duty crane to exchange a rotor with worn rolls for a new one ready for the next campaign. Coupled with a fast changing mandrel system, less than 5 minute size changes, mill downtime can be significantly reduced.

In terms of tooling, there are definite advantages to the KRM system. Mandrel material is hotworking tool steel. There is no need to chrome plate the mandrel. Because the working length is short, the mandrel can be easily redressed and used for a larger size product. Rolls can be reused from 20 - 40 times before reaching scrap size. A series of Hirth coupling plates allows rolls to be reduced in diameter and still used on the fixed rotor. 
Table I: Operating results

\begin{tabular}{|l|l|l|l|}
\hline \multicolumn{2}{|l|}{$\begin{array}{l}\text { Entry Size KRM } \\
\text { (hot) }\end{array}$} & \multicolumn{2}{l}{$\begin{array}{l}\text { Exit Size KRM/ EXB } \\
\text { (cold) }\end{array}$} \\
\hline OD & Wall & OD & Wall \\
\hline \multirow{4}{*}{$167.5 \varnothing$} & $25,5 \mathrm{~mm}$ & & $2.9 \mathrm{~mm}$ \\
& $29,5 \mathrm{~mm}$ & \multirow{4}{*}{$114.3 \varnothing$} & $12.0 \mathrm{~mm}$ \\
& & $11.0 \mathrm{~mm}$ \\
& $33,5 \mathrm{~mm}$ & & $18.0 \mathrm{~mm}$ \\
& & $17.0 \mathrm{~mm}$ \\
& & & $25.0 \mathrm{~mm}$ \\
\hline
\end{tabular}

\section{CONCLUSION}

The KRM is an innovative elongation method that allows very high quality production with a throughput that is not typically expected with more traditional elongation methods. Heavier billets and longer tubes are now possible in an elongator with a small footprint and low operating cost. The KRM is the perfect choice for a mid-range producer of high quality seamless steel tubes.

Abbreviations

$\mathrm{KRM}=$ Kocks Rotation Mill

$\mathrm{EXB}=$ Extracting Block / Extractor

$\mathrm{OD}=$ Outer Diameter

ID = Inner Diameter

tpy $=$ Tons per year

$\mathrm{SRB}^{\circledR}$ is a German trademark, registered by Kocks 